\title{
Processing urinary endoscopes in a low-temperature steam and formaldehyde autoclave
}

\author{
G. L. GIBSON \\ From the Regional Public Health Laboratory, Leeds
}

SUMMARY Methods of disinfection and sterilisation of urinary endoscopes are considered. A small mobile low-temperature steam and formaldehyde autoclave (Miniclave 80) is evaluated and shown to be satisfactory for this purpose as judged by a variety of relevant microbiological test pieces.

Considerable advances have been made over the last 20 years in techniques of sterilisation, in the organisation of sterile supply services, and in the design of instruments and the materials used in their manufacture. Nonetheless the problem of sterilisation of endoscopic instruments has not been completely solved. Indeed, as it has become easier to process some of the endoscopes of simpler nature and wellestablished design, more advanced instruments and fibrescopes have appeared, imposing new difficulties and limitations.

Urological endoscopes are of comparatively simple design, made in robust materials, and in frequent use. Ideally they always should be used in a sterile condition but it may be argued reasonably that it is sufficient that they should have undergone a process of disinfection, rendering them safe and free from organisms likely to be harmful in the urinary tract. They should be readily available for rapid turnover, and any disinfection process adopted should be available locally at the point of use so that instruments are not removed, transported, and delayed, requiring large numbers of duplicate instruments to provide a service. If necessary, the endoscope ought to be available in sterile or disinfected condition in a package suitable for storage.

Mitchell and Alder (1975), reviewing these criteria together with the obvious requirement that the method of processing should not damage the instrument or cause deterioration of the optical system, considered three possible methods of disinfection-immersion in chemical fluids, exposure to a disinfecting vapour, and exposure to a moist heat process at less than $100^{\circ} \mathrm{C}$.

The first of these must always be suspect because actual contact between the fluid and the organisms cannot be guaranteed throughout the instrument.

Received for publication 11 August 1976
There is often a damaging effect by the chemical on the optical system and the instruments must be thoroughly rinsed before use.

Exposure to ethylene oxide gas is, in proper conditions, a sterilising process. To use this dangerous gas in physical safety and to apply it in proper concentration and humidity requires expensive apparatus and a long cycle. Considerable microbiological monitoring support and a properly established sophisticated sterile supply service are needed to guarantee that the necessary conditions of precleaning and preparation are met and to ensure a proper airing off period after processing to allow the dispersal of the toxic gas from the instrument. Residual levels of ethylene oxide can be detected in a wide variety of materials for several days after processing (Gibson et al., 1968). Obviously steel is not a material likely to harbour excessive residual levels so that the problem with simple telescopes may not be a significant one. Also it is doubtful if any actual harm can be shown to result to the patient if an instrument contaminated with ethylene oxide is used on his urinary tract. Nevertheless this must remain a problem worthy of consideration. A further major disadvantage in practical terms of this method is the economic impossibility of providing acceptable ethylene oxide apparatus in the urological clinic.

In considering moist heat sterilisation, Mitchell and Alder (1975) make the point that, while some endoscopes can be autoclaved at normal instrument autoclave or porous load autoclave temperatures of $134^{\circ} \mathrm{C}$, many cannot withstand such a process. They fear that confusion between the two categories could result in expensive damage. It is important, therefore, that a method should be introduced which can be used to process all normal endoscopes. A modified method of moist heat sterilisation using lowtemperature steam or low-temperature steam and formaldehyde was first advocated for use in hospital 
by Alder and Gillespie in 1961 and was soon applied to a wide variety of instruments and apparatus (Alder et al., 1966; Gibson and Johnston, 1967). Recently the standard working temperature of the process has been reduced from $80^{\circ} \mathrm{C}$ to $73^{\circ} \mathrm{C}$ and this has been carried further by Weymes $(1975)$ to $65^{\circ} \mathrm{C}$ and below. The system used at $73^{\circ} \mathrm{C}$ offers a choice of two sound practical processes. Low-temperature steam alone will disinfect suitable instruments using short exposure times of 10,15 or 20 minutes. In conjunction with injected formaldehyde vapour the process will sterilise suitable instruments in a longer process of up to two hours. Some conditions must, of course, be met for the process to be effective. Sterilisation depends on actual penetration of the steam and the formaldehyde to the organism. Indeed it may be important that the formaldehyde should reach the organism in conditions of comparatively low humidity (Nordgren, 1939; Alder, 1968). From this point of view it is a pity that, for engineering reasons, standard autoclave design now achieves initial air removal by a process of steam pulsing with comparatively low vacuum rather than the single high vacuum of earlier days. The use of dry steam may be of vital importance to avoid higher humidity of the organisms as well as to avoid a reduction of formaldehyde concentration by its removal in solution.

\section{Material and methods}

A low-temperature steam and formaldehyde autoclave (Miniclave 80) was provided by Messrs Charles F. Thackray Ltd. This is a self-contained unit requiring only a $13 \mathrm{amp}$ power source. It incorporates reservoirs for water and formaldehyde solution BP $(36 \% \mathrm{w} / \mathrm{v})$ and a discharge tank and generates its own steam. It operates automatically and offers alternative cycles of low-temperature steam or low-temperature steam with formaldehyde vapour injection. The chamber size is $254 \mathrm{~mm}$ diameter by $460 \mathrm{~mm}$, giving a volume of $0.076 \mathrm{~m}^{3}$. A temperature of $73^{\circ} \mathrm{C} \pm 2^{\circ} \mathrm{C}$ is achieved at $427-513$ $\mathrm{mmHg}$ pressure. The overall dimensions are $760 \times$ $760 \times 560 \mathrm{~mm}$, and approximately 6 cycles are possible with one filling of the reservoirs. The instrument will accept three or four cystoscopes packed in foam rubber in cardboard boxes. It is mobile, weighing only $93 \mathrm{~kg}$ complete with stand (Figs. 1 and 2).

The cycle is variable but consists of six stages after an initial warming-up period of 15 minutes to reach $40^{\circ} \mathrm{C}$ when the machine becomes available for use:

1 Removal of air with steam pulses

2 Formaldehyde injection 0-18 $\mathrm{ml}$ available

3 Steam exposure time 5-210 minutes

4 Elution

5 Drying

6 Admission of air.

The machine is fitted with various safety devices. If the temperature reaches $80^{\circ} \mathrm{C}$, a cut-out operates; an alarm sounds if the processing conditions are not met, the cycle stops, and air is admitted. The door operates on a pressure-sealing system preventing opening except at atmospheric pressure.

The whole apparatus is small, self-contained, and relatively mobile and can be installed in any clinic

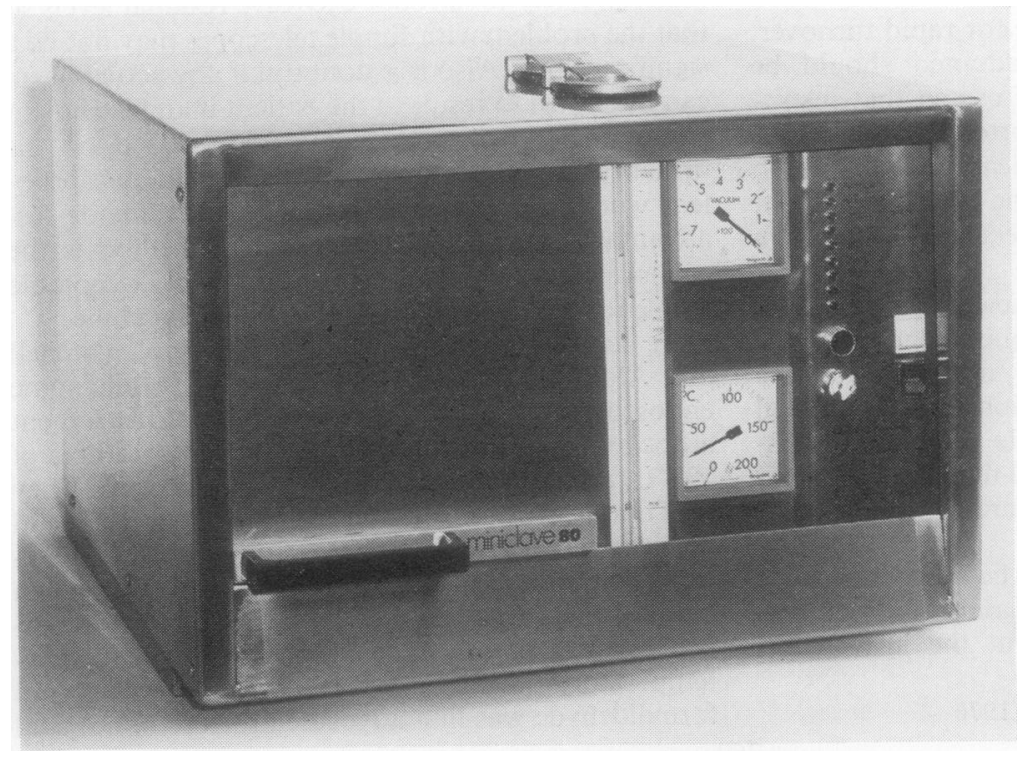

Fig. 1 Miniclave 80 showing control panel. 


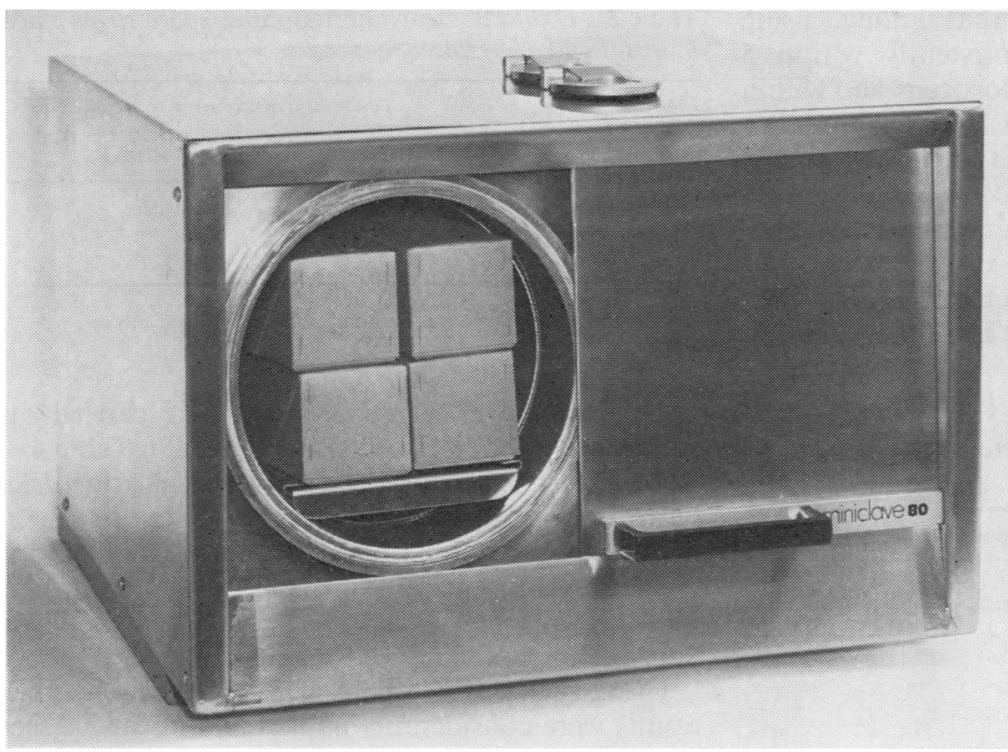

Fig. 2 Miniclave 80 loaded with four cystoscopes packed in boxes.

or other area which has a normal electric power socket.

In order to test the efficiency of the apparatus, a number of microbiological tests were carried out using a variety of test pieces. The design of test pieces and the interpretation of results obtained can only be a process of analogy. It is difficult to be dogmatic about what is a relevant test piece, and a number were used of varying degrees of severity.

1 A simple reproducible test piece was designed to test the ability of a routine cycle, using steam alone, to kill vegetative organisms in clean conditions in readily accessible situations.

Filter paper strips were inoculated with approximately $10^{5}$ cells of Staphylococcus aureus NTC 6571 and separate strips with a clinical isolate of a Streptococcus faecalis. These were placed in $10 \mathrm{ml}$

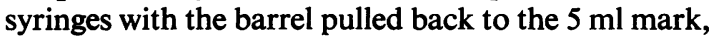
a 1 inch 23 gauge hypodermic needle with the plastic cover in place, and all sealed in a John Dickinson 'Sterilisation Pack' paper bag. Following autoclaving the paper strips were recovered and viability was tested by incubation in $10 \mathrm{ml}$ nutrient broth overnight at $37^{\circ} \mathrm{C}$ aerobically. This volume is considered sufficient to ensure dilution of any residual formaldehyde in the paper strip to an insignificant level.

2 A more exacting test piece, as evolved by Mitchell and Alder (1975), was employed consisting of a standard glass Universal container of $28 \mathrm{ml}$ capacity with a $17.8 \mathrm{~cm}$ length of $1 \mathrm{~mm}$ bore metal tubing soldered into the metal lid with a solid internal washer, ensuring an airtight seal except through the length of the tubing. Within this, Oxoid B stearother- mophilus spore strips were placed in $53 \times 9 \mathrm{~mm}$ cotton-wool-plugged glass tubes. The whole test piece was enclosed in foam rubber and packed in a cardboard 'cystoscope box' which was then enclosed in a paper bag as above. The spore strips were cultured in thioglycollate broth without indicator, incubated at $60^{\circ} \mathrm{C}$ for up to 10 days. This test piece would seem most nearly to reproduce the actual conditions of sterilisation of a cystoscope required to be prepackaged and subsequently stored in sterile conditions. Further tests were carried out using both the simple syringe test-piece and the Mitchell and Alder test-piece. This time the B. stearothermophilus spore strips were first soaked in sterile Oxoid horse serum and allowed to dry before being exposed and cultured as before.

3 A helix, as described by Line and Pickerill (1973), was employed using Oxoid B. stearothermophilus spore strips enclosed in the $1 \mathrm{ml}$ chamber and the whole helix was enclosed in a paper bag. Line and Pickerill showed that this test piece was actually more difficult to penetrate than an arterial catheter. It cannot, therefore, be entirely relevant in considering sterilisation of simple urinary telescopes.

With this in view, one of the modified helices, as described by Weymes et al. (1975), was obtained. This was re-designed to have a chamber size of 3.5 $\mathrm{ml}$, allowing easier penetration of the helix by steam and formaldehyde. Oxoid spore strips were also used in this helix.

\section{Results}

1 Tests with simple vegetative organisms in readily 
penetrated test pieces showed that killing, using steam alone, was achieved consistently within 5 minutes in the case of the staphylococcus and within 10 minutes in the case of the Streptococcus faecalis.

Using steam and formaldehyde to process simple syringe test pieces, killing of $B$. stearothermophilus on Oxoid spore strips was easily achieved at times from 5 up to 20 minutes, depending on the volume of formaldehyde injected into the chamber. The tests were carried out in quadruplicate and the results can be seen in Table 1 .

Table 1 B. stearothermophilus spore strips: syringe test piece

\begin{tabular}{|c|c|c|c|c|c|c|c|c|c|c|}
\hline \multirow{2}{*}{$\begin{array}{l}\text { Injection of } \\
\text { formaldehyde } \\
(m l)\end{array}$} & \multicolumn{10}{|c|}{ Time (min) of exposure to steam at $73^{\circ} \mathrm{C}$} \\
\hline & 5 & & 10 & & 15 & & 20 & & 30 & \\
\hline \multirow{2}{*}{3} & + & + & + & + & + & + & - & - & - & - \\
\hline & + & + & + & + & - & - & - & - & - & - \\
\hline \multirow{2}{*}{6} & + & + & + & + & - & - & - & - & - & - \\
\hline & + & + & + & + & - & - & - & - & - & - \\
\hline \multirow{2}{*}{9} & + & + & - & - & - & - & - & - & - & - \\
\hline & + & + & - & - & - & - & - & - & - & - \\
\hline \multirow[t]{2}{*}{12} & + & - & - & - & - & - & - & - & - & - \\
\hline & - & - & - & - & - & - & - & - & - & - \\
\hline \multirow[t]{2}{*}{15} & - & - & - & - & - & - & - & - & - & - \\
\hline & - & - & - & - & - & - & - & - & - & - \\
\hline
\end{tabular}

+ growth within four days; - no growth within four days

When serum soaked test pieces were employed, a longer period of steam exposure was required but there was less evidence of a need for a higher concentration of formaldehyde (see Table 2).

A number of similar tests were done with the same test pieces placed within the distal end of a suitable cystoscope and then enclosed in a John Dickinson 'Sterilisation Pack' paper bag and sealed. The tests were carried out in duplicate and the results can be seen in Table 3.

2 In order to simulate the conditions to be met in processing a cystoscope in its rubber-padded box, the test piece described by Mitchell and Alder was employed using $B$. stearothermophilus spore strips as above. Cultures were incubated for 10 days before
Table 3 Oxoid B. stearothermophilus spore strips placed in distal end of cystoscope

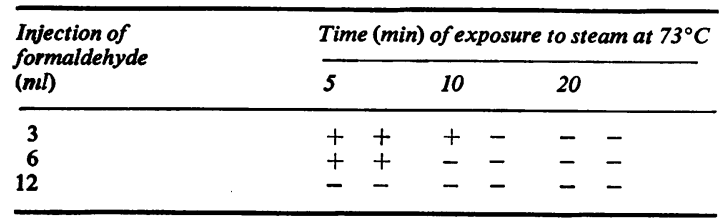

+ growth within four days; - no growth within four days

being accepted as negative. Tests were carried out in duplicate and the results can be seen in Table 4.

Table 5 shows similar tests carried out using dried serum-soaked $B$. stearothermophilus spore strips.

3 The results of tests using the standard Line and Pickerill helix with a $1 \mathrm{ml}$ chamber are shown in Table 6. The helix was double wrapped in paper. Spore strips were cultured for up to 10 days.

Using the modified helix with a $3.5 \mathrm{ml}$ chamber, results were considerably improved and can be seen in Table 7.

\section{Discussion}

The low-temperature steam and formaldehyde process offers a very satisfactory method of disinfecting and sterilising instruments which are sensitive to greater degrees of heat.

A wide variety of instruments can be processed without damage (Alder et al., 1966; Gibson and Johnston, 1967; Alder et al., 1971). They can be processed and used in a rapid turnover, as the apparatus required can be sited locally and as toxic residues are unlikely to constitute a serious problem with ordinary metal instruments.

The efficacy of the method as offered by the apparatus tested (Miniclave 80) appears to be acceptable. Of the variety of test pieces used, only the $1 \mathrm{ml}$ standard helix offered a challenge which could not consistently be met, and this type of test piece cannot be regarded as relevant to the processing of urinary endoscopes being designed to

Table 2 Serum-soaked B. stearothermophilus spore strips: syringe test piece

\begin{tabular}{|c|c|c|c|c|c|c|c|c|c|c|c|c|c|c|}
\hline \multirow[t]{2}{*}{ Injection of formaldehyde $(\mathrm{ml})$} & \multicolumn{14}{|c|}{ Time (min) of exposure to steam at $73^{\circ} \mathrm{C}$} \\
\hline & 5 & & 10 & & 15 & & 20 & & 30 & & 45 & & 60 & \\
\hline 3 & + & + & + & + & + & + & + & + & + & + & - & - & - & - \\
\hline 6 & + & + & + & + & + & + & + & + & - & + & - & - & - & - \\
\hline 9 & + & + & + & + & + & + & + & + & - & + & - & - & - & - \\
\hline 12 & + & + & + & + & + & + & + & + & + & + & - & - & - & - \\
\hline 15 & + & + & + & + & + & + & + & + & + & + & - & - & - & - \\
\hline
\end{tabular}


Table 4 B. stearothermophilus spore strips: Mitchell and Alder test piece

\begin{tabular}{|c|c|c|c|c|c|c|c|c|c|}
\hline \multirow[t]{2}{*}{ Injection of formaldehyde $(\mathrm{ml})$} & \multicolumn{9}{|c|}{ Time (min) of exposure to steam at $73^{\circ} \mathrm{C}$} \\
\hline & 10 & 20 & 30 & 40 & 50 & 60 & 70 & 90 & 120 \\
\hline $1 \cdot 5$ & + & + & + & + & + & + & + & - & - \\
\hline $3 \cdot 0$ & + & + & + & - & - & + & - & - & - \\
\hline 6.0 & + & - & - & - & - & - & - & - & - \\
\hline 9.0 & + & + & - & - & - & - & - & - & - \\
\hline $12 \cdot 0$ & + & + & - & - & - & - & - & - & - \\
\hline $15 \cdot 0$ & - & - & - & - & - & - & - & - & - \\
\hline 18.0 & - & - & - & - & - & - & - & - & - \\
\hline
\end{tabular}

+ growth in at least one test after 10 days; - no growth in either test after 10 days.

Table 5 Serum-soaked B. stearothermophilus spore strip: Mitchell and Alder test piece

\begin{tabular}{|c|c|c|c|c|}
\hline \multirow{2}{*}{$\begin{array}{l}\text { Injection of } \\
\text { formaldehyde } \\
(\mathrm{ml})\end{array}$} & \multicolumn{4}{|c|}{ Time (min) of exposure to steam at $73^{\circ} \mathrm{C}$} \\
\hline & 60 & 90 & 120 & 180 \\
\hline $1 \cdot 5$ & + & + & - & - \\
\hline $3 \cdot 0$ & + & + & + & - \\
\hline 6.0 & + & - & + & - \\
\hline 9.0 & + & - & - & - \\
\hline $12 \cdot 0$ & + & + & - & - \\
\hline 15.0 & + & + & - & - \\
\hline 18.0 & + & - & - & - \\
\hline
\end{tabular}

+ growth after 10 days; - no growth after 10 days

represent a more difficult test than that represented by an arterial catheter. The use of Browne Formaldehyde Test Papers (Albert Browne Ltd, Leicester LE4 OAA) in these helices bore out the belief that penetration of formaldehyde at least was more complete in the larger chamber. Penetration of the 1 $\mathrm{ml}$ chamber was generally incomplete, as judged by colour change in the test paper even after two hours' exposure, although good penetration of the modified chamber could be achieved. It is important when using these helices that they should be washed through with air for several minutes between tests. This serves to remove moisture which may reduce penetration and also removes any formaldehyde vapour which could give invalid results subsequently.

The other test pieces used showed that consistent, effective killing of spores and vegetative organisms can be achieved by the combination of formaldehyde and steam, provided these are able to penetrate to the organisms. The heat of the chamber alone is sufficient to destroy vegetative organisms rapidly, and

Table 6 Tests using $1.0 \mathrm{ml}$ chamber Line and Pickerill helix

\begin{tabular}{|c|c|c|c|c|c|c|c|c|c|c|c|}
\hline \multirow[t]{2}{*}{ Injection of formaldehyde $(\mathrm{ml})$} & \multicolumn{11}{|c|}{ Time (min) of exposure to steam at $73^{\circ} \mathrm{C}$} \\
\hline & 10 & 20 & 30 & 40 & 50 & 60 & 70 & 90 & 120 & 180 & 210 \\
\hline $1 \cdot 5$ & + & + & + & + & - & + & + & + & + & + & + \\
\hline 3.0 & + & + & + & - & + & + & + & + & - & + & + \\
\hline 6.0 & - & + & + & + & - & + & + & + & + & - & - \\
\hline $9 \cdot 0$ & + & + & - & + & + & + & + & + & + & + & + \\
\hline $12 \cdot 0$ & + & + & + & + & + & + & - & + & + & + & + \\
\hline 15.0 & $T$ & + & + & + & + & - & - & - & - & + & - \\
\hline $18 \cdot 0$ & + & + & + & + & + & - & - & + & - & - & - \\
\hline
\end{tabular}

+ growth; - no growth.

Table 7 Tests using $3.5 \mathrm{ml}$ chamber modified Line and Pickerill helix

\begin{tabular}{|c|c|c|c|c|c|c|c|c|c|c|c|}
\hline \multirow[t]{2}{*}{ Injection of formaldehyde $(\mathrm{ml})$} & \multicolumn{11}{|c|}{ Time (min) of exposure to steam at $73^{\circ} \mathrm{C}$} \\
\hline & 10 & 20 & 30 & 40 & 50 & 60 & 70 & 90 & 120 & 180 & 210 \\
\hline $1 \cdot 5$ & + & + & + & - & - & - & + & - & + & + & - \\
\hline $3 \cdot 0$ & + & + & + & - & + & - & + & - & - & - & - \\
\hline 6.0 & + & - & - & + & + & - & + & - & + & - & - \\
\hline 9.0 & + & - & + & - & - & - & - & + & - & - & - \\
\hline $12 \cdot 0$ & + & + & - & - & - & - & - & - & - & - & - \\
\hline 15.0 & - & - & - & - & - & - & - & - & - & - & - \\
\hline 18.0 & + & + & + & - & - & - & - & - & - & - & - \\
\hline
\end{tabular}

+ growth; - no growth. 
this effect is enhanced by formaldehyde vapour, but conducted heat alone is not enough to kill spores at the temperatures employed, and penetration of gas and steam is essential.

Experiments employing Mitchell and Alder's test piece and the simple syringe test piece, using Oxoid spore strips soaked in sterile Oxoid horse serum and allowed to dry, showed the protective effect of such dried protein and must reinforce the importance of adequate pre-cleaning of all instruments if sterilisation is to be achieved consistently.

Exposure to low-temperature steam and formaldehyde is the method of choice in processing urinary endoscopes. More robust endoscopes of other types could certainly also be processed by this means and should be designed as far as possible with this in mind. The apparatus evaluated here has the additional advantages of simplicity, mobility, comparatively low cost, and small size.

A short exposure time of 10-20 minutes using either steam alone or steam with formaldehyde provides a simple method of disinfection during a urological clinic and, as four cystoscopes can be processed at once, gives a sufficiently rapid turnover of instruments. A more prolonged time of exposure, such as two hours, with steam and formaldehyde offers a possible method of sterilising urinary endoscopes after use and retaining them in sterile condition until required.

\section{References}

Alder, V. G. (1968). Sterilisation by low temperature steam and formaldehyde under sub-atmospheric pressures at $80^{\circ} \mathrm{C}$. In Sterilisation Techniques for Instruments and Materials as Applied to Space Research. Cospar Technique Manual Series, No. 4, Paris, pp. 141-155.

Alder, V. G., Brown, A. M., and Gillespie, W. A. (1966). Disinfection of heat-sensitive material by low-temperature steam and formaldehyde. Journal of Clinical Pathology, 19, 83-89.

Alder, V. G. and Gillespie, W. A. (1961). Disinfection of woollen blankets in steam at subatmospheric pressure. Journal of Clinical Pathology, 14, 515-518.

Alder, V. G., Gingell, J. C., and Mitchell, J. P. (1971). Disinfection of cystoscopes by subatmospheric steam and steam and formaldehyde at $80^{\circ} \mathrm{C}$. British Medical Journal, 3, 677-680.

Gibson, G. L. and Johnston, H. P. (1967). Practical sterilisation by low temperature steam with formaldehyde. British Hospital Journal and Social Services Review, 77, 1208-1215.

Gibson, G. L., Johnston, H. P., and Turkington, V. E. (1968). Residual formaldehyde after low-temperature steam and formaldehyde sterilization. Journal of Clinical Pathology, 21, 771-775.

Line, S. J. and Pickerill, J. K. (1973). Testing a steamformaldehyde sterilizer for gas penetration efficiency. Journal of Clinical Pathology, 26, 716-720.

Mitchell, J. P. and Alder, V. G. (1975). The disinfection of urological endoscopes. British Journal of Urology, 47, 571-576.

Nordgren, G. (1939). Investigations on the sterilization efficacy of gaseous formaldehyde. Acta Pathalogica et Microbiologica Scandinavica, Supplement 40.

Weymes, C. (1975). Use of low temperature steam in the sterilisation of non-porous loads. Hospital Engineering, 29, 22-23.

Weymes, C., White, J. D., and Harris, C. (1975). Studies in the use of low concentrations of formaldehyde with steam at sub-atmospheric pressures as a method of sterilising non-porous heat sensitive items. In Note 4, Greater Glasgow Health Board Sterilisation Centre. 